\title{
The Neuroprotective Effects of Cinnamic Aldehyde in an MPTP Mouse Model of Parkinson's Disease
}

\author{
Woom-Yee Bae ${ }^{1,+}$, Jae-Sun Choi ${ }^{2,+}$ and Joo-Won Jeong ${ }^{1,2, *}$ \\ 1 Department of Biomedical Science, Graduate School, Kyung Hee University, Seoul 02447, Korea; \\ woom8875@khu.ac.kr \\ 2 Department of Anatomy and Neurobiology, College of Medicine, Kyung Hee University, Seoul 02447, \\ Korea;ChoiJS@khu.ac.kr \\ * Correspondence: jjeong@khu.ac.kr; Tel.: +82-2-961-9103 \\ + These authors equally contributed to this work.
}

Received: 29 January 2018; Accepted: 8 February 2018; Published: 12 February 2018

\begin{abstract}
Cinnamic aldehyde (CA), a key flavor compound in cinnamon essential oil, has been identified as an anti-oxidant, anti-angiogenic, and anti-inflammatory material. Recently, the neuroprotective effects of CA have been reported in various neurodegenerative disorders, including Parkinson's disease (PD). In neurons, autophagy is tightly regulated, and consequently, the dysregulation of autophagy may induce neurodegenerative disorders. In the present study, we found that the selective dopaminergic neuronal death in the substantia nigra of 1-methyl-4-phenyl-1,2,3,6-tetrahydropyridine (MPTP) mouse models was prevented by CA. Stimulation of microtubule-associated protein light chain 3 (LC3) puncta mediated by MPTP treatment was decreased by CA. Moreover, down-regulated p62 in the substantia nigra of MPTP mice was increased by administration of CA. Finally, we showed that blockage of autophagy using autophagy inhibitors protected the 1-methyl-4-phenylpyridinium $\left(\mathrm{MPP}^{+}\right)$-mediated death of BE(2)-M17 cells. Together these results suggest that CA has a neuroprotective effect in a PD model and that inhibition of autophagy might be a promising therapeutic target for PD.
\end{abstract}

Keywords: cinnamic aldehyde; autophagy; Parkinson's disease; MPTP; MPP ${ }^{+}$

\section{Introduction}

Parkinson's disease (PD) is a progressive neurodegenerative disorder and is characterized by selective dopaminergic neuronal loss in the substantia nigra and striatum of the brain, which leads to accountable motor symptoms, including bradykinesia, resting tremor, rigidity, and postural instability [1]. To date, researchers have attempted to find effective medicine for PD, and current therapies or drugs aim at stopping or slowing the progression of PD [2]. The main pathological pathway responsible for the dopaminergic neuronal death in PD is still unidentified [3]. Mounting evidence suggests that PD might be related to dysregulation of autophagy in neuronal cells, astrocytes, and microglial cells [4-6]. Therefore, recent studies on PD interventions have focused on the regulation and function of autophagy in PD.

1-Methyl-4-phenyl-1,2,3,6-tetrahydropyridine (MPTP) is a neurotoxin that has the ability to cross the blood-brain barrier and damage dopaminergic neurons in the nigrostriatal pathway [7]. MPTP is transformed by the enzyme monoamine peroxidase into 1-methyl-4-phenylpyridinium $\left(\mathrm{MPP}^{+}\right)$, which binds to dopamine transporters, causing the inhibition of dopamine uptake and depletion of its cerebral levels [8]. Because MPTP induces neurotoxicity in the nigrostriatal pathway and $\mathrm{MPP}^{+}$stimulates neuronal cell death, MPTP and $\mathrm{MPP}^{+}$are used to initiate PD in animal models and cellular models, respectively [9-12].

Because PD is the progressive disorder, investigators are searching for neuroprotective agents that are capable of stopping the underlying pathological condition and preventing further neuronal death. 
Most clinical drugs having neuroprotective effects are synthetic drugs that show undesirable adverse effects or toxicity $[13,14]$. Because natural products are considered to be relatively safe and effective, many researchers have tried to find their associated neuroprotective effects. Cinnamic aldehyde (cinnamaldehyde, CA) is a natural product extracted from Cinnamon trees $[15,16]$. As a yellow and viscous liquid, CA (Figure 1A) constitutes $98 \%$ of the essential oil of Cinnamon bark. Recently, CA was reported to protect individuals from neurodegenerative disorders, such as Alzheimer's disease and PD $[17,18]$. However, whether CA shows anti-PD activity or affects autophagy regulation is still unknown.

In the present study, the MPTP mouse model and the MPP ${ }^{+}$-induced cell injury model were used to examine the neuroprotective effects of CA in vivo and in vitro. We demonstrated that CA significantly reduced the selective dopaminergic cell death in the substantia nigra and striatum of the MPTP-administered mice. CA reduced LC3 puncta stimulated by MPTP and MPP ${ }^{+}$treatment, whereas $\mathrm{CA}$ increased $\mathrm{p} 62$ that had been reduced by MPTP and $\mathrm{MPP}^{+}$treatment. These findings suggest that CA could block dysregulated autophagy under PD conditions. In addition, inhibition of autophagy also reduced $\mathrm{MPP}^{+}$-mediated cell death. Collectively, our results indicated that $\mathrm{CA}$ is a novel natural product that regulates autophagy in cell death under PD conditions and that CA may be a promising agent for the treatment of PD.

\section{Results}

\subsection{CA Recovered MPP+'-Induced Cell Death in BE(2)-M17 Cells}

To evaluate the effects of CA on $\mathrm{MPP}^{+}$-induced neuronal cell death, we used BE(2)-M17 cells, a human neuroblastoma cell line. Cells were treated with various concentrations of CA for $48 \mathrm{~h}$, and the viability was examined by MTT assay. Because CA did not show any significant effects on cell viability up to $40 \mu \mathrm{M}$ (Figure 1B), we selected $10 \mu \mathrm{M}$ of CA for further experiments in this study. When the cells were exposed to $0.5 \mathrm{mM}$ of $\mathrm{MPP}^{+}$for $48 \mathrm{~h}$, cell viability was reduced by almost $50 \%$. The reduction of viability mediated by $\mathrm{MPP}^{+}$was significantly recovered by CA treatment (Figure 1C,D), indicating that $\mathrm{CA}$ attenuates $\mathrm{MPP}^{+}$-induced cell death in a cellular PD model.
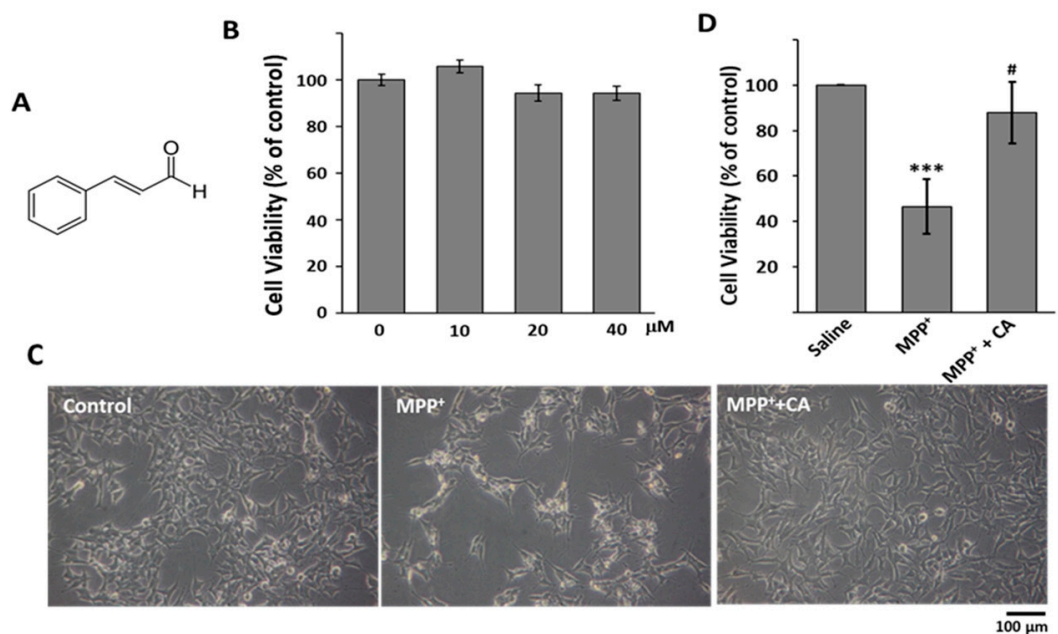

Figure 1. The effects of $\mathrm{CA}$ on $\mathrm{MPP}^{+}$-induced cell death. (A) The chemical structure of CA; (B) BE(2)-M17 cells were incubated with the indicated concentration of CA for $48 \mathrm{~h}$. The data are expressed as the means \pm standard deviation (S.D.) of three independent experiments; (C) $0.5 \mathrm{mM}$ $\mathrm{MPP}^{+}$was added to cells with $10 \mu \mathrm{M}$ of CA for $48 \mathrm{~h}$. Photos of cells were taken as indicated; (D) The live cell number was counted, and the data are expressed as the means \pm S.D. of three independent experiments. ${ }^{* * *} p<0.001$ versus control; ${ }^{\#} p<0.05$ versus $\mathrm{MPP}^{+}$-treated cells. 


\subsection{CA Protected against MPTP-Induced Dopaminergic Cell Death}

To clarify the neuroprotective effect of CA in PD, we used an MPTP mouse model. CA $(10 \mathrm{mg} / \mathrm{kg}$, i.p.) was administered daily for a week to MPTP-intoxicated mice. To examine whether CA is toxic in this animal model, we measured the hepatic toxicity marker enzymes, including aspartate aminotransferase (AST) and alanine aminotransaminase (ALT). As shown in Table 1, $10 \mathrm{mg} / \mathrm{kg}$ of CA did not show any cytotoxicity in the MPTP-treated mice. To identify the dopaminergic neuronal cell death in a mouse PD model, we stained the tissues of the substantia nigra and striatum using a specific antibody against tyrosine hydroxylase (TH), which is a marker for dopaminergic neurons. The administration of CA prevented the selective loss of TH-positive cell death mediated by MPTP injection in the substantia nigra (Figure 2A,B). Consistent with dopamine neuronal protection in the substantia nigra, CA prevented the severe loss of dopamine neuron fiber density from MPTP intoxication in the striatum (Figure 2C,D).

Table 1. The effects of CA treatment on the activities of aspartate aminotransferase (AST) and alanine aminotransaminase (ALT).

\begin{tabular}{ccc}
\hline Group & AST (IU/L) & ALT (IU/L) \\
\hline Saline & $26.9 \pm 6.0$ & $17.4 \pm 9.0$ \\
Saline + CA & $24.9 \pm 4.7$ & $12.2 \pm 0.9$ \\
MPTP & $28.6 \pm 2.7$ & $16.0 \pm 0.6$ \\
MPTP + CA & $30.8 \pm 6.4$ & $15.7 \pm 1.2$ \\
\hline
\end{tabular}

Values are means \pm S.D. for three mice in each group.

A

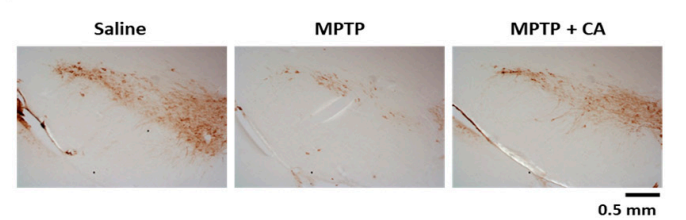

c

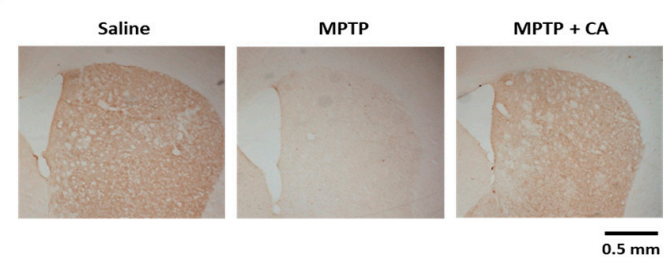

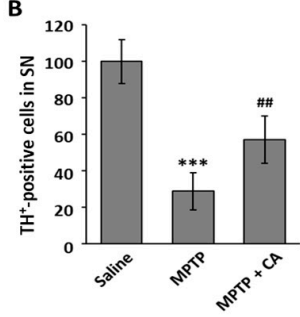

D

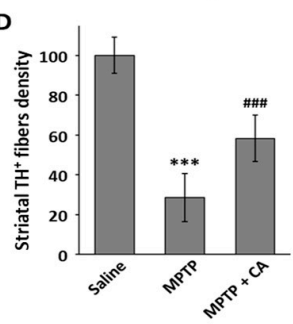

Figure 2. The effects of CA on dopaminergic cell death in an MPTP mouse model. (A) TH was stained using coronal substantia nigra sections from each group as indicated; (B) $\mathrm{TH}^{+}$-cell bodies were counted, and the data are expressed as the means \pm S.D. of three independent experiments. ${ }^{* * *} p<0.001$ versus saline group; ${ }^{\# \#} p<0.01$ versus the MPTP group; (C) Striatum sections of each group as indicated were stained with anti-TH antibody; (D) $\mathrm{TH}^{+}$fibers were quantified using ImageJ software. Quantitative values were normalized to $100 \%$ of saline mice. ${ }^{* * *} p<0.001$ versus saline group; \#\#\# $p<0.001$ versus MPTP group.

\subsection{CA Inhibits Autophagy Stimulated in the Substantia Nigra of MPTP-Treated Mice}

It is believed that autophagy is an important event in controlling cell death. Moreover, many recent studies have reported that autophagy is induced in MPTP-treated animals $[19,20]$. Therefore, we wanted to determine whether CA could regulate autophagy in a PD model. As shown in Figure 3A, LC3 puncta 
were stimulated in the substantia nigra of MPTP-treated mice. Conversely, treatment with CA decreased MPTP-induced LC3 puncta (Figure 3A). However, it was unclear whether the increase in LC3 puncta was associated with autophagy flux; therefore, we also examined the distribution of p62. The cytoplasmic expression level of p62 was decreased in MPTP-treated mice, and CA recovered the reduction of p62 expression (Figure 3B). From these results, we suggest that CA reduced autophagy stimulated in the MPTP mouse model.
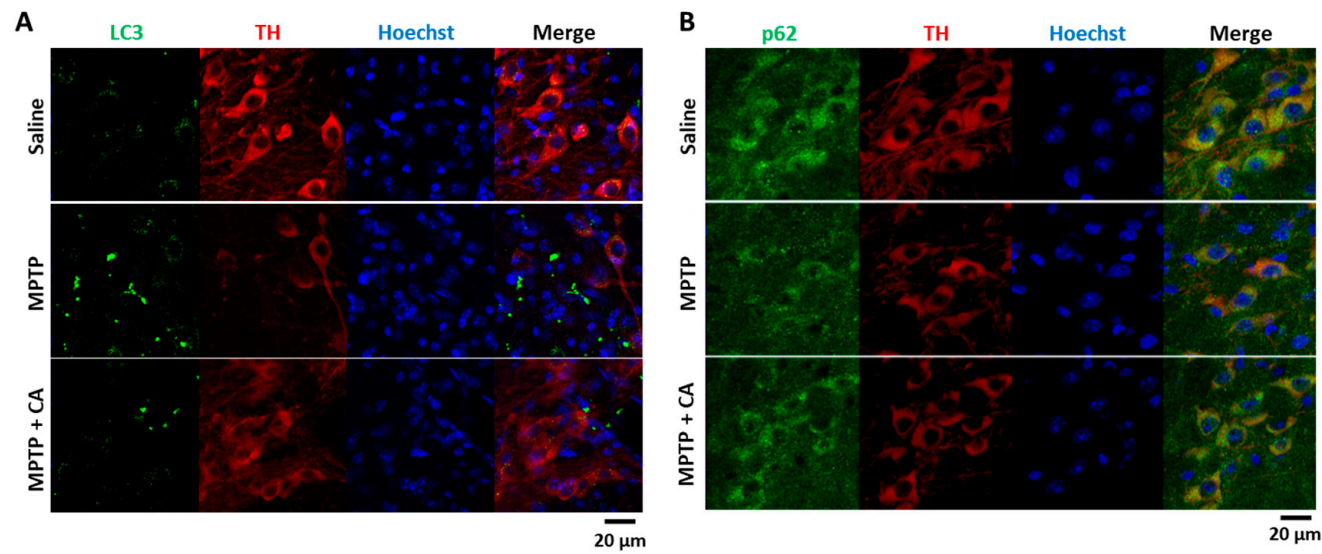

Figure 3. The effects of CA on autophagy in the substantia nigra of MPTP-treated mice. (A,B) Immunofluorescent staining was performed using specific antibodies. The substantia nigra tissues from each group were stained with anti-LC3 antibody (green, A), anti-p62 (green, B), anti-TH antibody (red), and Hoechst33342 (blue).

\subsection{CA Decreased Autophagy in MPP+-Treated BE(2)-M17 Cells}

Next, to explore whether CA regulates autophagy under PD conditions, we treated BE(2)-M17 cells with $\mathrm{MPP}^{+}$. After the LC3-GFP expression vector was transfected, LC3 puncta were examined by fluorescence microscopy and counted. As shown in Figure $4 \mathrm{~A}, \mathrm{~B}, \mathrm{MPP}^{+}$treatment stimulated the formation of LC3 puncta, and conversely, treatment with CA significantly decreased the puncta.

A

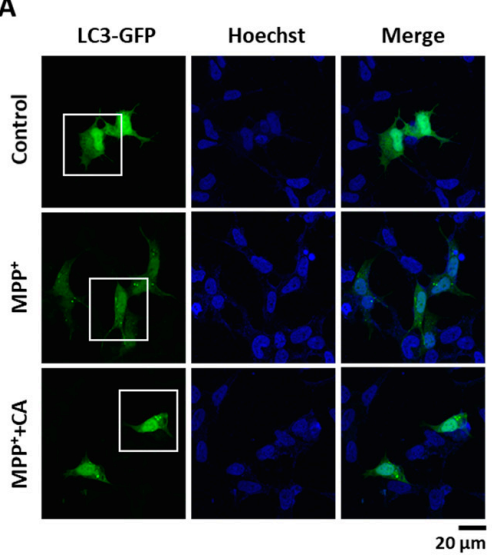

B

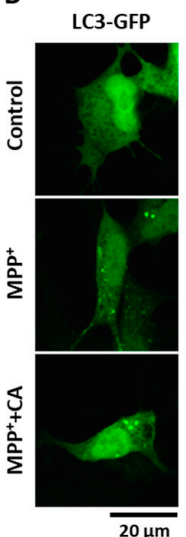

C

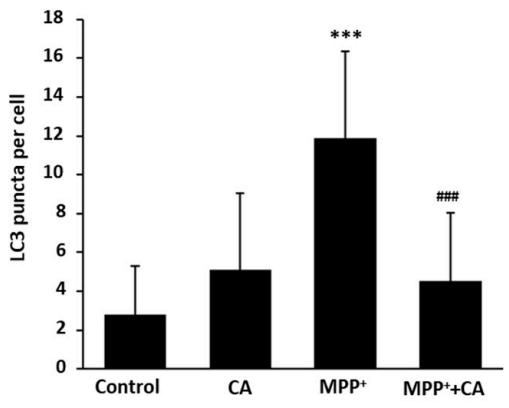

Figure 4. The effects of CA on LC3 puncta formation in an $\mathrm{MPP}^{+}$cellular PD model. (A) BE(2)-M17 cells were transfected with a GFP-tagged LC3 expression vector and then with either DMSO or $10 \mu \mathrm{M}$ of CA in the presence of $0.5 \mathrm{mM}$ of $\mathrm{MPP}^{+}$for $48 \mathrm{~h}$. LC3 puncta were visualized as a GFP signal. Cell nuclei (blue) were stained with Hoechst33342; (B) The magnified versions of white squares in (A); (C) The puncta with GFP signals in a cell were counted and graphed. ${ }^{* * *} p<0.001$ versus control; \#\#\# $p<0.001$ versus $\mathrm{MPP}^{+}$-treated cells. 
When p62 protein expression was examined using immunofluorescence, we found that $\mathrm{p} 62$ was decreased in $\mathrm{MPP}^{+}$-treated cells. Moreover, $\mathrm{CA}$ recovered the reduction of p62 in $\mathrm{MPP}^{+}$-treated cells (Figure 5A). To examine the expression of autophagy-related proteins, we performed Western blotting analysis. As shown in Figure 5B, beclin 1, ATG5, and ATG7 were not changed by CA in the presence of $\mathrm{MPP}^{+}$. However, p62 was decreased by $\mathrm{MPP}^{+}$and recovered by $\mathrm{CA}$ (Figure $5 \mathrm{~B}$ ), suggesting that $\mathrm{CA}$ inhibits autophagy in $\mathrm{MPP}^{+}$-induced cell death.
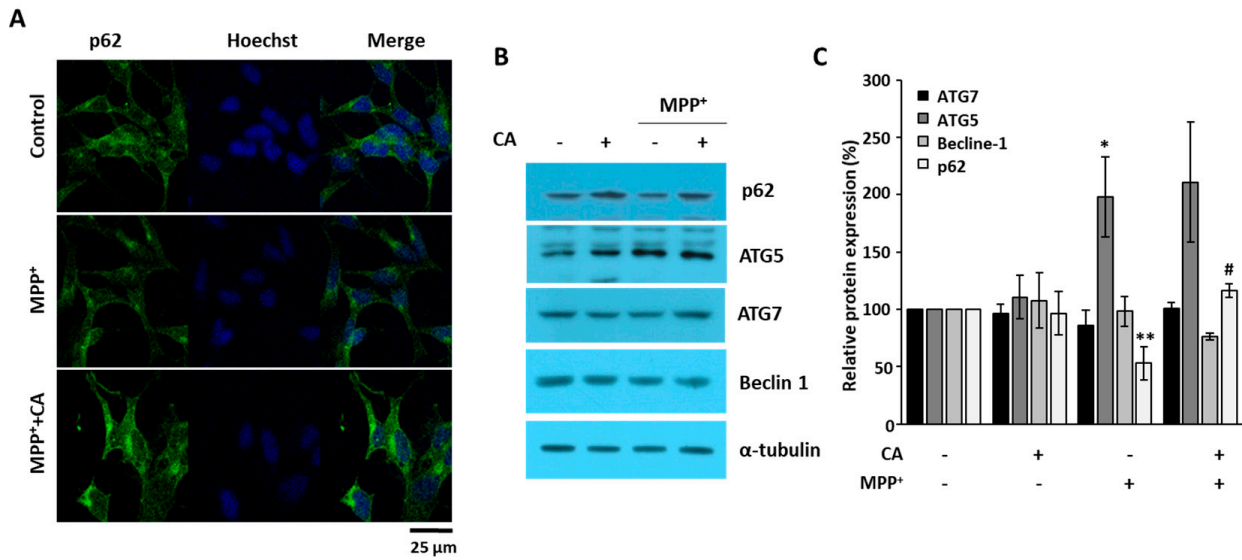

Figure 5. The effects of CA on autophagy-related protein expression. (A) BE(2)-M17 cells were treated with either vehicle or $10 \mu \mathrm{M}$ of $\mathrm{CA}$ in the presence of $0.5 \mathrm{mM}$ of $\mathrm{MPP}^{+}$for $48 \mathrm{~h}$. Intracellular expression of p62 (green) was determined by immunofluorescent staining using a specific antibody. Cell nuclei (blue) were stained with Hoechst33342; (B) Western blots from whole cell lysates were performed using anti-p62, -beclin 1, -ATG5, -ATG7, and anti- $\alpha$-tubulin antibodies; (C) Relative expression was quantified and plotted. ${ }^{*} p<0.05,{ }^{* *} p<0.01$ versus control; ${ }^{\#} p<0.05$ versus $\mathrm{MPP}^{+}$-treated cells.

\subsection{Inhibition of Autophagy Suppressed MPP ${ }^{+}$-Induced Cell Death}

We already found that CA decreased $\mathrm{MPP}^{+}$-mediated cell death and inhibited autophagy stimulated by $\mathrm{MPP}^{+}$. Therefore, we wanted to assess whether inhibition of autophagy affected $\mathrm{MPP}^{+}$-mediated cell death. In the same manner as the treatment with $\mathrm{CA}$, bafilomycin A1 and 3-MA significantly recovered $\mathrm{MPP}^{+}$-mediated BE(2)-M17 cell death (Figure 6A,B). However, chloroquine could not recover the cell death. Collectively, we suggested that CA suppressed $\mathrm{MPP}^{+}$-induced cell death by blocking autophagy.
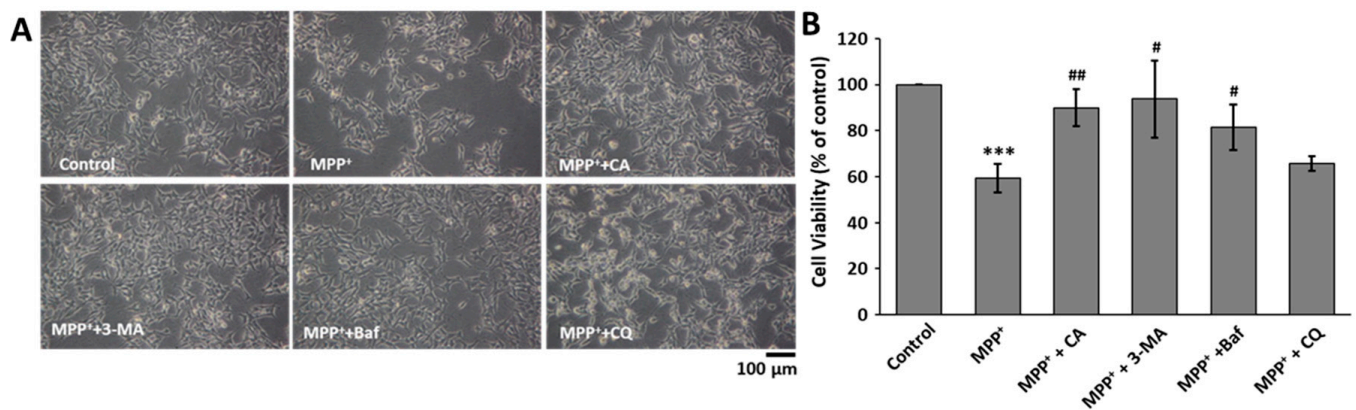

Figure 6. The effects of autophagy inhibitors on $\mathrm{MPP}^{+}$-induced cell death. (A) BE(2)-M17 cells were treated with $10 \mathrm{nM}$ of bafilomycin A1, $1 \mathrm{mM}$ of 3-MA, $10 \mu \mathrm{M}$ chloroquine, and $10 \mu \mathrm{M}$ of CA in the presence of $0.5 \mathrm{mM}$ of $\mathrm{MPP}^{+}$for $48 \mathrm{~h}$. Photos were taken of the cell morphologies under each condition. Baf: bafilomycin A1; CQ: chloroquine; (B) The live cell number was counted, and the data are expressed as the means \pm S.D. of three independent experiments. ${ }^{* * *} p<0.001$ versus control; ${ }^{*} p<0.05,{ }^{\# \#} p<0.01$ versus $\mathrm{MPP}^{+}$-treated cells. 


\section{Discussion}

Accumulating studies indicated that misfolding of $\alpha$-synuclein, imbalanced autophagy, and mitochondrial dysfunction are deeply involved in the pathogenesis of PD [21]. Therapies such as oral L-dopa and deep brain stimulation are used in the clinic to improve motor complications of PD [22]. However, these therapies are not ideal to stop or slow down PD and even show side effects such as dyskinesia and morning akinesia. Natural products are considered relatively safe with limited side effects and may become potential drugs for PD treatment. Here, we selected CA in our study to understand its influence on MPTP- and $\mathrm{MPP}^{+}$-induced PD models. We, for the first time, found that CA significantly rescued $\mathrm{MPP}^{+}$-induced cell death and MPTP-induced dopaminergic cell death (Figures 1 and 2).

The major physiological role of autophagy is recycling intracellular energy resources in response to conditions of nutrient depletion [23]. Another function is degradation of cytotoxic proteins and damaged organelles under stress conditions [24]. The pathogenesis of numerous neurodegenerative diseases has been linked cytoplasmic and nuclear inclusions composed of aggregated or polyubiquitinated proteins. These include amyloid plaques of Alzheimer's disease and the Lewy bodies of PD. The protein aggregations in these diseases are involved in synaptic dysfunction and neuronal degeneration. According to the recent reports, autophagy-related mechanisms lead to pathological alterations of neurodegeneration $[25,26]$. In this study, we wanted to know whether CA could regulate autophagy under PD conditions. In MPTP-administered mice and MPP ${ }^{+}$-injured cells, LC3 puncta were strongly increased, and the protein level of p62 was decreased (Figures 3-5). These autophagic changes were recovered with the administration of $\mathrm{CA}$, indicating that $\mathrm{CA}$ rehabilitates dysregulated autophagy under PD conditions.

Recently, many reports have shown that autophagy is induced under PD conditions, including with $\mathrm{MPP}^{+}$treatment and in MPTP mice $[27,28]$. However, the function of stimulated autophagy is not clear. Neurons require a basal level of autophagic degradation to mediate replacement of damaged components or to facilitate synaptic remodeling. Under PD conditions, the neuronal loss in the substantia nigra is partly due to the accumulation of aggregated and/or misfolded proteins [21]. Most aggregated and/or misfolded proteins are cleaned via two important pathways: the ubiquitin proteasome system and the autophagy-lysosome pathway [29]. Because misfolded $\alpha$-synuclein can be cleared by the autophagic pathway [30], it is easily predicted that autophagy will induce cell survival in PD. However, in the present study, we found that autophagy inhibitors such as 3-MA and bafilomycin A1 rescued $\mathrm{MPP}^{+}$-induced cell death in BE(2)-M17 cells (Figure 6). In addition, at the identical concentrations we used in this study, these autophagy inhibitors had no significant effect on basal BE(2)-M17 cell viability. These results were consistent with the recent report that neither 3-MA nor wortmannin were able to inhibit the increase in autophagic vacuoles induced by $\mathrm{MPP}^{+}$[31]. Moreover, a recent report suggested that stimulated autophagy induces cell death in $\mathrm{MPP}^{+}$-treated human neuroblastoma cells [32]. In many diseases, autophagy is stimulated by various stress conditions, and autophagic cell death is induced [33-35]. However, many reports were inconsistent with our data $[36,37]$. This inconsistency may be attributed to the analysis of different cell types and conditions among the studies. In addition, autophagy can induce either cell survival or cell death depending on the environment [38], and autophagic stress often induces impaired degradation of misfolded proteins [39]. The mechanisms and functions of autophagic perturbation are not mutually exclusive.

In the present study, MPTP and MPP+ were able to induce autophagy in neuronal cells, which was shown to exert cellular death under PD conditions. In addition, CA was able to protect dopaminergic neuronal cells from the toxic effects of $\mathrm{MPP}^{+}$by reducing the rate of autophagy, thus supporting the hypothesis that autophagy induced by $\mathrm{MPP}^{+}$treatment may stimulate cell death. The results of the present study may help to elucidate the important role of autophagy under PD conditions and to direct the development of a novel strategy to treat patients with PD. Moreover, we strongly support the future use of CA for the treatment of PD and related complications. 


\section{Materials and Methods}

\subsection{Materials}

$\mathrm{MPP}^{+}, \mathrm{MPTP}, \mathrm{CA}$, bafilomycin A1, 3-methyladenine (3-MA), and chloroquine were purchased from Sigma Aldrich (St Louis, MO, USA). Antibodies for tyrosine hydroxylase (TH) was purchased from Cell Signaling Technology (Beverly, MA, USA). Antibodies recognizing p62, beclin 1, ATG5, and ATG7 were obtained from Santa Cruz Biotechnology (Dallas, TX, USA). A mammalian expression vector for LC3-GFP was kindly provided by Joohun Ha (Kyung Hee University, Seoul, Korea).

\subsection{Cell Culture, Transfection, and Treatment}

Human neuroblastoma BE(2)-M17 cells were maintained in Dulbecco's modified Eagle's medium (WelGENE, Korea) supplemented with 10\% fetal bovine serum (HyClone, Logan, UT, USA) and antibiotics at $37{ }^{\circ} \mathrm{C}$ in a humidified atmosphere of $95 \%$ air and $5 \% \mathrm{CO}_{2} \cdot \mathrm{MPP}^{+}$and CA were added to the cells for $48 \mathrm{~h}$. Transient transfection of the LC3-GFP expression vector was conducted using the polyethylenimine method. The cells were also treated with bafilomycin A1,3-MA, or chloroquine in the presence of $\mathrm{MPP}^{+}$.

\subsection{3-(4,5-Dimethylthiazol-2-yl)-2,5-Diphenyltetrazolium Bromide (MTT) Assay}

$\mathrm{BE}(2)-\mathrm{M} 17$ cells were treated with $\mathrm{MPP}^{+}$for $48 \mathrm{~h}$, and MTT (0.1 mg/mL; Sigma Aldrich) was added to each well and incubated at $37^{\circ} \mathrm{C}$ for $2 \mathrm{~h}$. The media were removed, and DMSO was added to each well. The absorbance was measured at $560 \mathrm{~nm}$ using an iMark Microplate Absorbance Reader (Bio-Rad, Hercules, CA, USA).

\subsection{Animals and MPTP Mouse Model}

Ten-week-old male C57BL/ 6 mice ( $n=4-5$ per group) were purchased from Daehan Bio-link (Chungbuk, Korea). All experiments were performed in accordance with the approved animal protocols and guidelines established by Kyung Hee University (KHUASP(SE)-17-018, 26-04-2017). For MPTP intoxication, the mice received four intraperitoneal injections (i.p.) of MPTP (20 mg/kg) at $2 \mathrm{~h}$ intervals, as previously reported [40,41]. Injections of CA $(10 \mathrm{mg} / \mathrm{kg}$, i.p.) were delivered daily for 7 days after MPTP injection.

\subsection{Immunohistochemistry and Immunofluorescent Analyses}

Animals were transcardially perfused with $4 \%$ paraformaldehyde. Brains were then isolated, frozen, and cut into $30 \mu \mathrm{m}$ slices on a freezing microtome (Leica Microsystems, Bensheim, Germany). The sections ( $n=3-4$ per mouse) were then incubated with PBS containing $0.3 \%$ Triton X-100 for 20 min and stained with specific antibodies against TH, LC3, and p62. The antigen sites were visualized either with the VECTASTAIN Elite ABC Kit (VECTOR laboratories, Burlingame, CA, USA) and 3,3-diaminobenzidine (Sigma-Aldrich, St Louis, MO, USA) or with Alexa-488 (Invitrogen, Eugene, OR, USA) and Alexa-594 (Invitrogen). The intensity of each staining was measured using ImageJ software 1.51n (Wayne Rasbang, NIH, Bethesda, MD, USA).

\subsection{Western Blotting Analysis}

Total proteins were isolated from the indicated cells using the lysis buffer (10 mM Tris, $10 \mathrm{mM} \mathrm{NaCl}$ and $0.2 \% \mathrm{NP}-40$ ) containing a protease inhibitor cocktail (Sigma Aldrich) and phosphatase inhibitors $\left(1 \mathrm{mM} \mathrm{Na}_{3} \mathrm{VO}_{4}\right.$ and $\left.10 \mathrm{mM} \mathrm{NaF}\right)$. The equal amounts of total proteins were separated by SDS-PAGE, and were transferred onto a PVDF membrane (Millipore Corporation, Billerica, MA, USA). The membranes were blocked with $5 \%$ bovine serum albumin (BSA) in Tris-buffered saline containing $0.1 \%$ tween 20 (TBS-T) and incubated overnight at $4{ }^{\circ} \mathrm{C}$ with primary antibodies diluted in blocking buffer. The membranes were washed and incubated with the appropriate HRP-conjugated secondary 
antibodies for $1 \mathrm{~h}$ at room temperature. The signal was detected using an ECL Western detection system (Thermo Scientific, Rockford, IL, USA).

\subsection{Statistical Analysis}

All experiments were performed at least three times. The results were expressed as the means \pm S.D. Differences between groups were examined for statistical significance using a $t$-test. $p$-values $<0.05$ were considered statistically significant.

Acknowledgments: We thank Joohun Ha (Kyung Hee University, Korea) for the gift of the LC3-GFP expression vector. This work was supported by Basic Science Research Program through the National Research Foundation of Korea (NRF) funded by the Ministry of Education (NRF-2016R1A6A3A11930351, Jae-Sun Choi) and by the NRF grant funded by the Korea government (MIST) (NRF-2017R1A2B4006692, Joo-Won Jeong).

Author Contributions: Woom-Yee Bae, Jae-Sun Choi and Joo-Won Jeong designed the experiments; Woom-Yee Bae and Jae-Sun Choi performed the experiments and analyzed the data; Joo-Won Jeong wrote the paper.

Conflicts of Interest: The authors declare no conflict of interest.

\section{Abbreviations}

$\begin{array}{ll}\text { CA } & \text { Cinnamic Aldehyde } \\ \text { PD } & \text { Parkinson's Disease } \\ \text { MPTP } & \text { 1-methyl-4-phenyl-1,2,3,6-tetrahydropyridine } \\ \text { MPP }^{+} & \text {1-methyl-4-phenylpyridinium } \\ \text { TH } & \text { tyrosine hydroxylase }\end{array}$

\section{References}

1. Subramaniam, S.R.; Chesselet, M.F. Mitochondrial dysfunction and oxidative stress in Parkinson's disease. Prog. Neurobiol. 2013, 106-107, 17-32. [CrossRef] [PubMed]

2. Savitt, J.M.; Dawson, V.L.; Dawson, T.M. Diagnosis and treatment of Parkinson disease: Molecules to medicine. J. Clin. Investig. 2006, 116, 1744-1754. [CrossRef] [PubMed]

3. Jellinger, K.A. Pathology of Parkinson's disease. Changes other than the nigrostriatal pathway. Mol. Chem. Neuropathol. 1991, 14, 153-197. [CrossRef] [PubMed]

4. Di Malta, C.; Fryer, J.D.; Settembre, C.; Ballabio, A. Autophagy in astrocytes: A novel culprit in lysosomal storage disorders. Autophagy 2012, 8, 1871-1872. [CrossRef] [PubMed]

5. Ghavami, S.; Shojaei, S.; Yeganeh, B.; Ande, S.R.; Jangamreddy, J.R.; Mehrpour, M.; Christoffersson, J.; Chaabane, W.; Moghadam, A.R.; Kashani, H.H.; et al. Autophagy and apoptosis dysfunction in neurodegenerative disorders. Prog. Neurobiol. 2014, 112, 24-49. [CrossRef] [PubMed]

6. Nash, Y.; Schmukler, E.; Trudler, D.; Pinkas-Kramarski, R.; Frenkel, D. DJ-1 deficiency impairs autophagy and reduces $\alpha$-synuclein phagocytosis by microglia. J. Neurochem. 2017, 143, 584-594. [CrossRef] [PubMed]

7. Schmidt, N.; Ferger, B. Neurochemical findings in the MPTP model of Parkinson's disease. J. Neural Transm. (Vienna) 2001, 108, 1263-1282. [CrossRef] [PubMed]

8. Nakamura, S.; Vincent, S.R. Histochemistry of MPTP oxidation in the rat brain: Sites of synthesis of the parkinsonism-inducing toxin $\mathrm{MPP}^{+}$. Neurosci. Lett. 1986, 65, 321-325. [CrossRef]

9. An, L.; Liu, S.; Dong, Y.; Tang, B.; Dong, W. Protective effect of effective part of Acanthopanacis senticosus on damage of PC12 cells induced by MPP+. Zhongguo Zhong Yao Za Zhi 2010, 35, 2021-2026. [PubMed]

10. Betarbet, R.; Sherer, T.B.; Greenamyre, J.T. Animal models of Parkinson's disease. Bioessays 2002, 24, 308-318. [CrossRef] [PubMed]

11. Burns, R.S.; Chiueh, C.C.; Markey, S.P.; Ebert, M.H.; Jacobowitz, D.M.; Kopin, I.J. A primate model of parkinsonism: Selective destruction of dopaminergic neurons in the pars compacta of the substantia nigra by N-methyl-4-phenyl-1,2,3,6-tetrahydropyridine. Proc. Natl. Acad. Sci. USA 1983, 80, 4546-4550. [CrossRef] [PubMed]

12. Du, T.; Li, L.; Song, N.; Xie, J.; Jiang, H. Rosmarinic acid antagonized 1-methyl-4-phenylpyridinium $\left(\mathrm{MPP}^{+}\right)$-induced neurotoxicity in MES23.5 dopaminergic cells. Int. J. Toxicol. 2010, 29, 625-633. [CrossRef] [PubMed] 
13. Mandel, S.; Amit, T.; Bar-Am, O.; Youdim, M.B. Iron dysregulation in Alzheimer's disease: Multimodal brain permeable iron chelating drugs, possessing neuroprotective-neurorescue and amyloid precursor protein-processing regulatory activities as therapeutic agents. Prog. Neurobiol. 2007, 82, 348-360. [CrossRef] [PubMed]

14. Zheng, H.; Gal, S.; Weiner, L.M.; Bar-Am, O.; Warshawsky, A.; Fridkin, M.; Youdim, M.B. Novel multifunctional neuroprotective iron chelator-monoamine oxidase inhibitor drugs for neurodegenerative diseases: In vitro studies on antioxidant activity, prevention of lipid peroxide formation and monoamine oxidase inhibition. J. Neurochem. 2005, 95, 68-78. [CrossRef] [PubMed]

15. Bickers, D.; Calow, P.; Greim, H.; Hanifin, J.M.; Rogers, A.E.; Saurat, J.H.; Sipes, I.G.; Smith, R.L.; Tagami, H.; RIFM Expert, Panel. A toxicologic and dermatologic assessment of cinnamyl alcohol, cinnamaldehyde and cinnamic acid when used as fragrance ingredients. Food Chem. Toxicol. 2005, 43, 799-836. [CrossRef] [PubMed]

16. Peters, M.M.; Caldwell, J. Studies on trans-cinnamaldehyde. 1. The influence of dose size and sex on its disposition in the rat and mouse. Food Chem. Toxicol. 1994, 32, 869-876. [CrossRef]

17. George, R.C.; Lew, J.; Graves, D.J. Interaction of cinnamaldehyde and epicatechin with tau: Implications of beneficial effects in modulating Alzheimer's disease pathogenesis. J. Alzheimers Dis. 2013, 36, 21-40. [CrossRef] [PubMed]

18. Pyo, J.H.; Jeong, Y.K.; Yeo, S.; Lee, J.H.; Jeong, M.Y.; Kim, S.H.; Choi, Y.G.; Lim, S. Neuroprotective effect of trans-cinnamaldehyde on the 6-hydroxydopamine-induced dopaminergic injury. Biol. Pharm. Bull. 2013, 36, 1928-1935. [CrossRef] [PubMed]

19. Wen, Z.; Shu, Y.; Gao, C.; Wang, X.; Qi, G.; Zhang, P.; Li, M.; Shi, J.; Tian, B. CDK5-mediated phosphorylation and autophagy of RKIP regulate neuronal death in Parkinson's disease. Neurobiol. Aging 2014, 35, 2870-2880. [CrossRef] [PubMed]

20. Wong, A.S.; Lee, R.H.; Cheung, A.Y.; Yeung, P.K.; Chung, S.K.; Cheung, Z.H.; Ip, N.Y. Cdk5-mediated phosphorylation of endophilin B1 is required for induced autophagy in models of Parkinson's disease. Nat. Cell Biol. 2011, 13, 568-579. [CrossRef] [PubMed]

21. Michel, P.P.; Hirsch, E.C.; Hunot, S. Understanding dopaminergic cell death pathways in Parkinson Disease. Neuron 2016, 90, 675-691. [CrossRef] [PubMed]

22. Oertel, W.; Schulz, J.B. Current and experimental treatments of Parkinson disease: A guide for neuroscientists. J. Neurochem. 2016, 139, 325-337. [CrossRef] [PubMed]

23. Kuma, A.; Hatano, M.; Matsui, M.; Yamamoto, A.; Nakaya, H.; Yoshimori, T.; Ohsumi, Y.; Tokuhisa, T.; Mizushima, N. The role of autophagy during the early neonatal starvation period. Nature 2004, 432, 1032-1036. [CrossRef] [PubMed]

24. Kroemer, G.; Marino, G.; Levine, B. Autophagy and the integrated stress response. Mol. Cell 2010, 40, $280-293$. [CrossRef] [PubMed]

25. Chu, C.T. Autophagic stress in neuronal injury and disease. J. Neuropathol. Exp. Neurol. 2006, 65, 423-432. [CrossRef] [PubMed]

26. Nixon, R.A. Autophagy, amyloidogenesis and Alzheimer disease. J. Cell Sci. 2007, 120, 4081-4091. [CrossRef] [PubMed]

27. Dagda, R.K.; Das Banerjee, T.; Janda, E. How Parkinsonian toxins dysregulate the autophagy machinery. Int. J. Mol. Sci. 2013, 14, 22163-22189. [CrossRef] [PubMed]

28. Hung, K.C.; Huang, H.J.; Lin, M.W.; Lei, Y.P.; Lin, A.M. Roles of autophagy in $\mathrm{MPP}^{+}$-induced neurotoxicity in vivo: The involvement of mitochondria and alpha-synuclein aggregation. PLoS ONE 2014, 9, e91074. [CrossRef] [PubMed]

29. Klionsky, D.J.; Emr, S.D. Autophagy as a regulated pathway of cellular degradation. Science 2000, 290, 1717-1721. [CrossRef] [PubMed]

30. Bandyopadhyay, U.; Cuervo, A.M. Chaperone-mediated autophagy in aging and neurodegeneration: Lessons from alpha-synuclein. Exp. Gerontol. 2007, 42, 120-128. [CrossRef] [PubMed]

31. Zhu, J.H.; Horbinski, C.; Guo, F.; Watkins, S.; Uchiyama, Y.; Chu, C.T. Regulation of autophagy by extracellular signal-regulated protein kinases during 1-methyl-4-phenylpyridinium-induced cell death. Am. J. Pathol. 2007, 170, 75-86. [CrossRef] [PubMed] 
32. Nopparat, C.; Porter, J.E.; Ebadi, M.; Govitrapong, P. 1-Methyl-4-phenylpyridinium-induced cell death via autophagy through a Bcl-2/Beclin 1 complex-dependent pathway. Neurochem. Res. 2014, 39, $225-232$. [CrossRef] [PubMed]

33. Chen, Y.; McMillan-Ward, E.; Kong, J.; Israels, S.J.; Gibson, S.B. Oxidative stress induces autophagic cell death independent of apoptosis in transformed and cancer cells. Cell Death Differ. 2008, 15, 171-182. [CrossRef] [PubMed]

34. Law, B.Y.; Chan, W.K.; Xu, S.W.; Wang, J.R.; Bai, L.P.; Liu, L.; Wong, V.K. Natural small-molecule enhancers of autophagy induce autophagic cell death in apoptosis-defective cells. Sci. Rep. 2014, 4, 5510. [CrossRef] [PubMed]

35. Ma, S.; Dielschneider, R.F.; Henson, E.S.; Xiao, W.; Choquette, T.R.; Blankstein, A.R.; Chen, Y.; Gibson, S.B. Ferroptosis and autophagy induced cell death occur independently after siramesine and lapatinib treatment in breast cancer cells. PLoS ONE 2017, 12, e0182921. [CrossRef] [PubMed]

36. Castino, R.; Lazzeri, G.; Lenzi, P.; Bellio, N.; Follo, C.; Ferrucci, M.; Fornai, F.; Isidoro, C. Suppression of autophagy precipitates neuronal cell death following low doses of methamphetamine. J. Neurochem. 2008, 106, 1426-1439. [CrossRef] [PubMed]

37. Dadakhujaev, S.; Noh, H.S.; Jung, E.J.; Cha, J.Y.; Baek, S.M.; Ha, J.H.; Kim, D.R. Autophagy protects the rotenone-induced cell death in alpha-synuclein overexpressing SH-SY5Y cells. Neurosci. Lett. 2010, 472, 47-52. [CrossRef] [PubMed]

38. Das, G.; Shravage, B.V.; Baehrecke, E.H. Regulation and function of autophagy during cell survival and cell death. Cold Spring Harb. Perspect. Biol. 2012, 4. [CrossRef] [PubMed]

39. Cherra, S.J., III; Chu, C.T. Autophagy in neuroprotection and neurodegeneration: A question of balance. Future Neurol. 2008, 3, 309-323. [CrossRef] [PubMed]

40. Choi, J.S.; Park, C.; Jeong, J.W. AMP-activated protein kinase is activated in Parkinson's disease models mediated by 1-methyl-4-phenyl-1,2,3,6-tetrahydropyridine. Biochem. Biophys. Res. Commun. 2010, 391, 147-151. [CrossRef] [PubMed]

41. Jackson-Lewis, V.; Przedborski, S. Protocol for the MPTP mouse model of Parkinson's disease. Nat. Protoc. 2007, 2, 141-151. [CrossRef] [PubMed]

(C) 2018 by the authors. Licensee MDPI, Basel, Switzerland. This article is an open access article distributed under the terms and conditions of the Creative Commons Attribution (CC BY) license (http:/ / creativecommons.org/licenses/by/4.0/). 